\title{
Characterization and Photophysical Properties of a Luminescent Aluminum Hydride Complex Supported by a $\beta$-Diketiminate Ligand
}

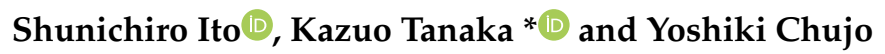 \\ Department of Polymer Chemistry, Graduate School of Engineering, Kyoto University, Katsura, Nishikyo-ku, \\ Kyoto 615-8510, Japan \\ * Correspondence: tanaka@poly.synchem.kyoto-u.ac.jp; Tel.: +81-75-383-2604
}

Received: 29 July 2019; Accepted: 14 August 2019; Published: 17 August 2019

\begin{abstract}
Aluminum hydrides are versatile compounds utilized as reducing agents, precursors of aluminum complexes, and as catalysts for polymerization reactions. However, their photophysical properties have been overlooked, although several luminescent aluminum complexes have been utilized conventionally for emitting layers in modern light-emitting devices. Herein, we report the synthesis and photophysical properties of a luminescent $\beta$-diketiminate dihydride complex through the reaction between lithium aluminum hydride and the corresponding ligand. The obtained compound exhibits crystallization-induced emission (CIE) properties at room temperature and long-lifetime phosphorescence at $80 \mathrm{~K}$. Our experimental and theoretical investigations suggest that low-energy molecular vibration could play an important role in the realization of the CIE property.
\end{abstract}

Keywords: aluminum dihydrides; photophysical property; crystallization-induced emission

\section{Introduction}

Organic and inorganic aluminum complexes have attracted a tremendous amount of attention as not only a catalyst for organic and polymerization reactions, but also as a luminescent material, owing to their specific reactivities, the abundance of aluminum in the earth's crust, and their low environmental burden. Aluminum hydrides have been one of the most important reducing agents in organic chemistry, and some of the most important precursors of various types of complexes since Schlesinger et al. synthesized lithium aluminum hydride in 1947 [1,2]. Furthermore, a group of luminescent aluminum complexes has shed new light on the chemistry and physics of organic light-emitting diodes (OLEDs) since tris(8-quinolinolato) aluminum $\left(\mathrm{Alq}_{3}\right)$ was applied to an emitting layer of light-emitting diodes [3-5]. Because of the superior electron-carrier ability and the luminescent properties, $\mathrm{Alq}_{3}$ is currently known as the conventional material for constructing modern OLEDs. Most of these complexes, however, exhibit weaker emission intensity as solids than in dilute solutions, although most potential applications require efficient luminescence in the condensed state. The disappearance of the luminescence of the molecules is caused by intermolecular interaction in the condensed state. Indeed, there are still a limited number of stable aluminum complexes that exhibit sufficient emission properties [4]. Thus, it is essential to develop a new class of solid-state luminescent aluminum complexes.

$\beta$-Diketiminate ligands, also known as $\beta$-diiminate or "nacnac" ligands, have been utilized to construct a wide variety of unstable complexes containing main-group and transition metals. These complexes have been applied for diverse chemical reactions, e.g., activation of inert chemical bonds, catalytic hydroboration [6], and polymerization [7-16]. In particular, since the monomeric $\beta$-diketiminate aluminum(I) complex was isolated in 2000 [17], the activation of a variety of inert chemical bonds have been established by using aluminum(I) complexes. Now, various kinds of 
four-coordinated aluminum(III) complexes have been obtained by the bond-activation method [18-21]. However, the optical and electronic properties of these complexes have been ignored, probably because they exhibit a slight absorption band in the visible region due to the limited $\pi$-conjugation length of the $\beta$-diketiminate ligands.

Recently, solid-state emissive $\beta$-diketiminate complexes composed of four-coordinate group 13 elements, boron and gallium, have been reported [22-28]. It has been clarified that the extension of the $\pi$-conjugated system involving $\beta$-diketiminate ligands makes the corresponding complexes luminescent in the visible region. Most importantly, these complexes emit weakly in dilute solution. Meanwhile, they present efficient emission in solids. Furthermore, their emission quantum yields are higher in the crystalline state than in the amorphous state. These enhancement behaviors by aggregation and by crystallization are called aggregation-induced emission (AIE) and crystallization-induced emission (CIE), respectively. These luminescent characteristics have been paid much attention because of their potential application in the field of OLEDs, fluorescent sensors, bioimaging, and lasers [29-32]. The bulky peripheral aromatic substituents in these molecules consume the excited energy via molecular vibration in the solution. In contrast, the aggregation and the crystallization restrict the intramolecular vibration, and the hindered groups expel the intermolecular interactions, which lead to severe concentration quenching in the condensed state for typical luminescent molecules [30]. As a result, intense solid-state emission is obtained from these systems. Furthermore, it has been found that the luminescence intensity and colors are able to be varied with high sensitivity toward environmental changes by modulating the degree of molecular motions and morphology [33-40]. Thus, these complexes are expected to be a promising scaffold for developing stimulus-responsive optical materials, as well as solid-state luminescent dyes.

Based on the information and the enormous potential of aluminum complexes, we introduced the aluminum complexes into the chemistry of the AIE and CIE properties. We envisioned that $\pi$-extended $\beta$-diketiminate ligands could serve as a scaffold for obtaining efficient solid-state emission properties from complexes containing aluminum atoms. In order to achieve this aim, we designed and synthesized a $\beta$-diketiminate aluminum dihydride composed of a bulky and $\pi$-extended ligand. Herein, it is demonstrated that the synthesized complex exhibited a CIE property at room temperature. Moreover, this compound showed long-lifetime phosphorescence at $80 \mathrm{~K}$, despite the absence of heavy atoms in the molecular structure. This is the first report on the luminescent aluminum dihydride complex. Our experimental and theoretical investigation suggest that intramolecular vibrational modes of the complex might be one of the key factors responsible for the nonradiative decay process in the solution state.

\section{Results and Discussion}

\subsection{Synthesis and Characterization}

According to the earlier study [41], with a minor modification, the aluminum dihydride complex LAlH was prepared by the reaction of the $\beta$-diketiminate ligand [42] and an excess amount of lithium aluminum hydride in toluene at $90{ }^{\circ} \mathrm{C}$ (Scheme 1). From the results of the ${ }^{1} \mathrm{H}$ NMR measurements, the ligand was completely consumed in $16 \mathrm{~h}$. After recrystallization, compound LAlH was fully characterized by ${ }^{1} \mathrm{H},{ }^{13} \mathrm{C}\left\{{ }^{1} \mathrm{H}\right\}$ and ${ }^{27} \mathrm{Al}\left\{{ }^{1} \mathrm{H}\right\}$ NMR spectroscopy and high-resolution mass spectrometry with the DART (Direct Analysis in Real-Time) method. The ${ }^{1} \mathrm{H}$ NMR spectrum showed the broad resonance at $4.74 \mathrm{ppm}$ attributed to $\mathrm{AlH}$ [43]. Such peak broadening should be due to the quadrupolar feature of ${ }^{27} \mathrm{Al}(\mathrm{I}=5 / 2)$. In the ${ }^{27} \mathrm{Al}\left\{{ }^{1} \mathrm{H}\right\} \mathrm{NMR}$, the broad peak was observed at around $65 \mathrm{ppm}$, which is the characteristic value for four-coordinated aluminum nuclei [44] and is similar to that of the related $\beta$-diketiminate aluminum hydride complex [41]. The complex is storable under an inert atmosphere in both $\mathrm{C}_{6} \mathrm{D}_{6}$ solution and crystalline states at room temperature without any decomposition. 

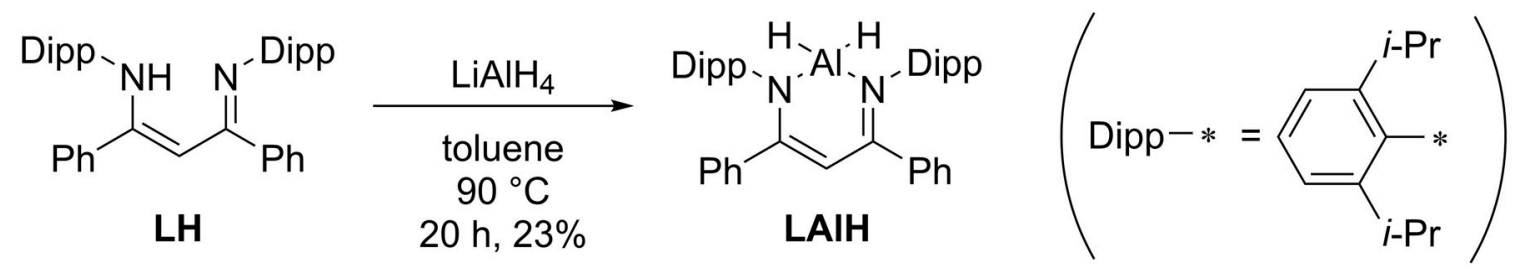

Scheme 1. Synthetic scheme of an aluminum hydride complex.

The molecular structure of LAlH was determined by single-crystal X-ray analysis. The bright yellow crystals of LAlH suitable for the analysis were grown from the mixed solvent of toluene and hexane by cooling from 25 to $10{ }^{\circ} \mathrm{C}$. The compound crystallized in the orthorhombic space group Pbca (CCDC number: 1946518). The asymmetric unit consists of one crystallographically independent molecule, and its structure and the structural parameters are shown in Figure 1a and Table 1. The single-crystal structure of the complex shows three structural features: (i) a planar $\mathrm{C}_{3} \mathrm{~N}_{2}$ $\pi$-conjugated system, (ii) displaced coordination at the $\mathrm{Al}$ center, and (iii) a propeller-shaped ligand. Firstly, the $\mathrm{C}_{3} \mathrm{~N}_{2}$ moiety of the central six-membered ring is nearly planar. As shown in Table 1, the $\mathrm{CN}$ and $\mathrm{CC}$ bond lengths are intermediate values between their normal single and double bond lengths. These facts indicate that delocalization of $\pi$-electrons along with the $\beta$-diketiminate moiety, which possesses the isoelectronic structure of the pentadienyl anion [45]. Secondly, the aluminum atom is displaced from the $\mathrm{C}_{3} \mathrm{~N}_{2}$ plane, and a dihedral angle between the $\mathrm{C}_{3} \mathrm{~N}_{2}$ and $\mathrm{AlN}_{2}$ planes is $23.95^{\circ}$, probably because of the steric hindrance of the diisopropylphenyl and the phenyl groups. Such a distorted structure was not observed in the previously reported structures of $\beta$-diketiminate aluminum dihydrides [41,46,47], while similar distortion has frequently been observed in the sterically encumbered dihalogen, dialkyl, and other metal complexes [48]. On the other hand, the Al-N lengths and the $\mathrm{N}-\mathrm{Al}-\mathrm{N}$ coordination angles are within the natural values of the reported dihydride complexes $[41,46,47]$. Finally, it is worth noting that the dihedral angles between the $C_{3} N_{2}$ plane and the peripheral aromatic rings lie within the range $40.29^{\circ}-81.48^{\circ}$. Such a propeller-like structure would prohibit the undesired intermolecular interactions that cause the concentration quenching of emission, e.g., $\pi-\pi$ stacking and excimer formation [30]. Indeed, all chromophores seem to be distinctly isolated in the crystal structure (see Figure S4).

a

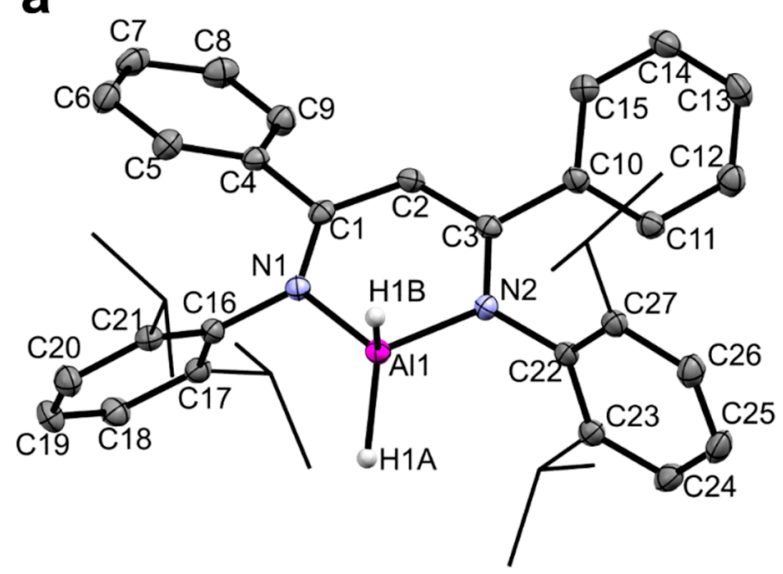

b

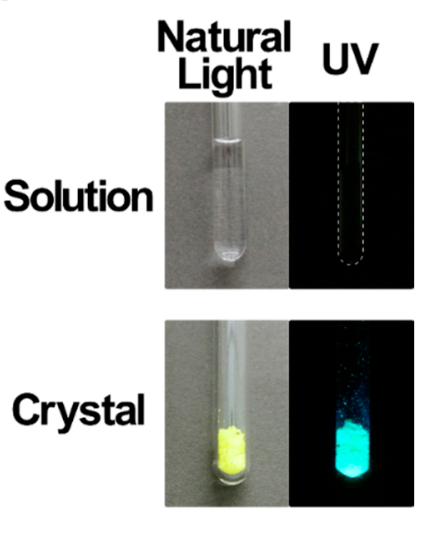

Figure 1. (a) Oak Ridge Thermal Ellipsoid Plot (ORTEP) (50\% ellipsoids) of compound LAlH. For clarity, isopropyl groups were shown in wireframe and hydrogen atoms were omitted except for those at the aluminum atom. Key to atom colors: carbon, gray; aluminum, magenta; nitrogen, blue; and hydrogen, white. (b) Photographic images of the 2-methylpentane/toluene $(99 / 1)$ solution $\left(1 \times 10^{-5} \mathrm{M}\right)$ and the crystals under natural light (left) and UV irradiation (right). 
Table 1. Selected structural parameters of LAlH in the single crystal.

\begin{tabular}{ccc}
\hline \multicolumn{2}{c}{ Distances } & \\
\hline Atom1 & Atom2 & Length/A \\
\hline Al1 & N1 & $1.898(1)$ \\
Al1 & N2 & $1.899(1)$ \\
N1 & C1 & $1.339(2)$ \\
N2 & C3 & $1.334(2)$ \\
C1 & C2 & $1.405(2)$ \\
C2 & C3 & $1.410(2)$ \\
\hline
\end{tabular}

\begin{tabular}{cccc}
\hline Angles & \multicolumn{3}{c}{} \\
\hline Atom1 & Atom2 & Atom3 & Angle/deg \\
\hline N1 & Al1 & N2 & $96.84(5)$ \\
A11 & N1 & C1 & $121.98(8)$ \\
Al1 & N2 & C3 & $121.01(8)$ \\
N1 & C1 & C2 & $122.3(1)$ \\
N2 & C3 & C2 & $122.5(1)$ \\
C1 & C2 & C3 & $127.9(1)$
\end{tabular}

\begin{tabular}{ccc}
\hline \multicolumn{2}{c}{ Dihedral Angles } & \\
\hline Plane1 $^{a}$ & Plane2 $^{b}$ & $\begin{array}{c}\text { Dihedral } \\
\text { Angle/deg }\end{array}$ \\
\hline $\mathrm{C}_{3} \mathrm{~N}_{2}$ & $\mathrm{AlN}_{2}$ & 23.95 \\
$\mathrm{C}_{3} \mathrm{~N}_{2}$ & $\mathrm{C} 4-9$ & 40.29 \\
$\mathrm{C}_{3} \mathrm{~N}_{2}$ & $\mathrm{C} 10-15$ & 45.99 \\
$\mathrm{C}_{3} \mathrm{~N}_{2}$ & $\mathrm{C} 16-21$ & 81.48 \\
$\mathrm{C}_{3} \mathrm{~N}_{2}$ & $\mathrm{C} 22-27$ & 69.84 \\
\hline
\end{tabular}

$a \overline{\mathrm{C}_{3} \mathrm{~N}_{2} \text { plane consists of } \mathrm{N} 1, \mathrm{C} 1, \mathrm{C} 2, \mathrm{C} 3 \text {, and } \mathrm{N} 2 \text { atoms. }{ }^{b} \mathrm{AlN}_{2} \text { plane consists of Al1, N1 and } \mathrm{N} 2 \text { atoms. }}$

\subsection{Photophysical Properties}

LAlH showed clear crystallization-induced emission property. The crystals of LAlH exhibited bright bluish-green emission upon UV irradiation $(365 \mathrm{~nm})$ at room temperature, while its solution (2-methylpentane/toluene $=99 / 1 ; 1 \times 10^{-5} \mathrm{M}$ ) showed no emission at the same temperature (Figure $1 \mathrm{~b}$ ). The crystallization probably restricts inter- and intramolecular motion and vibration, which nonradiatively consume the excited state energy of the molecules in the solution state at room temperature $[22,23,25,26]$. We provide a further explanation for this phenomenon in the following discussion.

To elucidate the photophysical characteristics of LAlH, the UV-Vis absorption spectrum of the solution and photoluminescence spectra of both the solution and the crystals were recorded (Figure 2a, Table 2). Photoexcitation was carried out at $380 \mathrm{~nm}$ for the luminescence spectroscopy. The absorption band was peaked at $394 \mathrm{~nm}$ and showed no clear vibronic structure at room temperature. Under the same conditions, a quite weak and broad emission band was detected at around $457 \mathrm{~nm}$. A natural radiative decay constant $\left(k_{\mathrm{FL}}^{0}\right)$ can be estimated using the Strickler-Berg (SB) equation (see Supporting Material) [49]:

$$
k_{\mathrm{FL}}^{0}=2.880 \times 10^{-9} n^{2} \widetilde{v}^{2} \frac{g_{l}}{g_{u}} \int \epsilon(\widetilde{v}) d \widetilde{v}
$$

where $n$ represents the refractive index of the solvent, $\widetilde{v_{0}}$ denotes the photon energy in wavenumber at an absorption maximum, $g_{l}$ and $g_{u}$ are the degeneracies of the lower and upper states of interest, and $\epsilon(\widetilde{v})$ is the molar absorption coefficient as a function of wavenumber. The calculated value is $1.9 \times 10^{8} \mathrm{~s}^{-1}$, and this large $k_{\mathrm{FL}}^{0}$ clearly means this electronic transition is allowed. The absolute quantum yield of $\mathbf{L A l H}$, however, is less than 0.01 in the solution at room temperature. This result 
indicates that the singlet excited state should be decayed through critical nonradiative paths under this condition, like vibronic coupling and conical intersections.

a

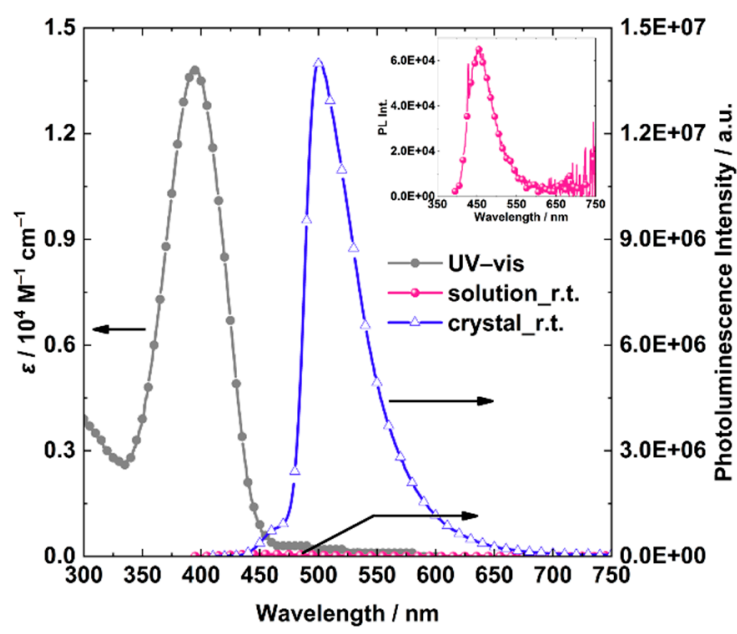

b

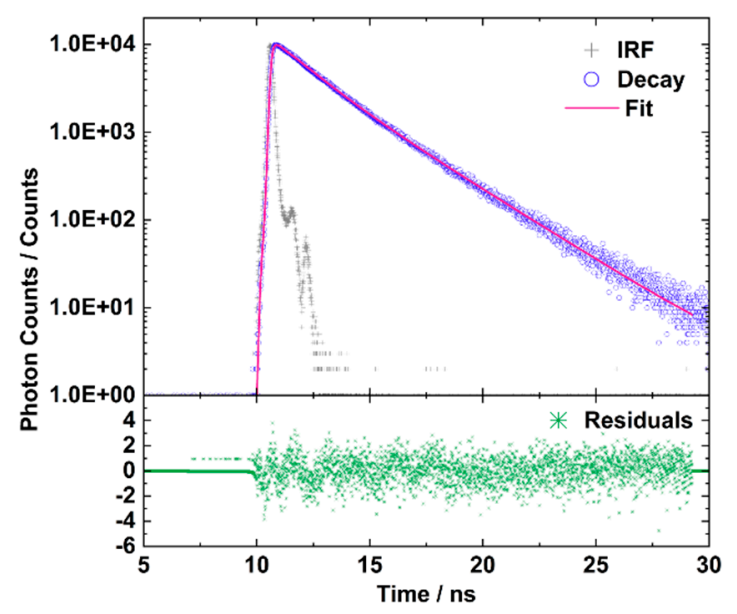

Figure 2. (a) UV-vis spectrum in $1 \times 10^{-5}$ M 2-methylpentane/toluene (99/1, v/v) solution (gray, - - $)$, and photoluminescence spectra in the solution (magenta, $-\bigcirc_{-}$) and in the crystalline states (blue, $-\Delta_{-}^{-}$). Inset shows an enlarged view of the photoluminescence spectrum in the solution state (magenta, $-\bigcirc-$ ). (b) A photoluminescence decay curve (blue, $\bigcirc$ ) in the crystalline state at room temperature is shown with an instrument response function (gray, +), an exponential fitting curve (magenta, - ), and residuals of the fitting (green, $x$ ).

Table 2. Photophysical properties of LAlH at room temperature.

\begin{tabular}{ccccccc}
\hline & & $\lambda_{\mathbf{a b s}} / \mathbf{n m}{ }^{a}$ & $\begin{array}{c}\varepsilon_{\text {max }} / \mathbf{1 0}^{\mathbf{4}} \\
\mathbf{M}^{\mathbf{- 1}} \mathbf{c m}^{-\mathbf{1} b}\end{array}$ & $\lambda_{\mathbf{e m}} / \mathbf{n m}{ }^{c}$ & $\boldsymbol{\Phi}_{\mathbf{F L}}{ }^{d}$ & $\boldsymbol{\Phi}_{\mathbf{P h o s}}{ }^{d}$ \\
\hline \multirow{2}{*}{ solution $^{e}$} & r.t. & 394 & 1.4 & 457 & $<0.01$ & $<0.01$ \\
& $80 \mathrm{~K}$ & $-f$ & $-f$ & 430,449 & 0.80 & 0.13 \\
\hline \multirow{2}{*}{ crystal } & r.t. & $-f$ & $-f$ & 501 & 0.34 & $<0.01$ \\
& $80 \mathrm{~K}$ & $-f$ & $-f$ & 456,479 & 0.83 & $<0.01$ \\
\hline
\end{tabular}

${ }^{a}$ Absorption maximum wavelength. ${ }^{b}$ Molar absorption coefficient at $\lambda_{\text {abs. }}{ }^{c}$ Emission maximum excited at $380 \mathrm{~nm}$.

${ }^{d}$ Absolute photoluminescence quantum yield excited at $\lambda_{\mathrm{abs}} \cdot{ }^{e} 1 \times 10^{-5} \mathrm{M}$ in 2-methylpentane/toluene (99/1, v/v).

${ }^{f}$ Not determined.

Meanwhile, the emission spectrum in the crystalline state exhibited a strong maximum at $501 \mathrm{~nm}$ and a distinct weak peak around $460 \mathrm{~nm}$. These two distinct peaks might be assigned to the same luminescent species because of the similar values of their fluorescence lifetimes (Figure S6 and Table S4). The absolute fluorescence quantum efficiency $\Phi_{\mathrm{FL}}$ of the crystals was determined to be 0.34 at room temperature when the crystals were excited at $394 \mathrm{~nm}$. The average fluorescence lifetime $\langle\tau\rangle$ was $2.3 \mathrm{~ns}$ (Figure $2 \mathrm{~b}$ and Table 3). Considering the simple photophysical picture (Figure S7), the fluorescence rate constant $k_{\mathrm{FL}}^{S}$ can be estimated by the following equations.

$$
\begin{gathered}
\langle\tau\rangle=\left(k_{\mathrm{FL}}+k_{\mathrm{nr}}^{S}+k_{\mathrm{ISC}}\right)^{-1} \\
k_{\mathrm{FL}}=\Phi_{\mathrm{FL}} /\langle\tau\rangle
\end{gathered}
$$

where $k_{\mathrm{nr}}^{S}$ and $k_{\mathrm{ISC}}$ are the nonradiative decays from the singlet excited state and intersystem crossing rate constants, respectively. The estimated $k_{\mathrm{FL}}$ value is $1.5 \times 10^{8} \mathrm{~s}^{-1}$, which is comparable to the calculated $k_{\mathrm{FL}}^{0}$ value from the SB equation, vide supra. 
Table 3. Photoluminescence lifetimes and kinetic constants of LAlH.

\begin{tabular}{|c|c|c|c|c|c|c|c|}
\hline & & $\tau_{1} / \mathrm{ns} ; f_{1}(\%)^{a}$ & $\tau_{2} / \mathrm{ns} ; f_{2}(\%)^{a}$ & $\chi^{2 b}$ & $<\tau>/$ ns $^{c}$ & $\begin{array}{c}k_{\mathrm{FL}} / 10^{8} \\
\mathrm{~s}^{-1} d\end{array}$ & $\begin{array}{c}k_{\mathrm{nr}} \mathrm{S} / 10^{8} \\
\mathrm{~s}^{-1} e\end{array}$ \\
\hline solution & $80 \mathrm{~K}$ & $1.43^{f} ; 7.72^{f}$ & $3.27^{f} ; 87.32^{f}$ & 1.20 & 3.0 & 2.7 & $<0.68$ \\
\hline \multirow{2}{*}{ crystal } & r.t. & $1.39 ; 31.07$ & $2.75 ; 68.93$ & 1.01 & 2.3 & 1.5 & 2.8 \\
\hline & $80 \mathrm{~K}$ & $2.07 ; 21.07$ & $3.27 ; 78.93$ & 0.94 & 3.0 & 2.8 & 0.56 \\
\hline
\end{tabular}

${ }^{a}$ Photoluminescence decay curve was fitted with two-exponential decay function: $I(t)=I_{0} \sum \alpha_{i} \exp \left(-t / \tau_{i}\right) . f_{i}{ }^{\prime} \mathrm{s}$ are fractions of each component $i$, which can be written as follows: $f_{i}=\alpha_{i} \tau_{i} / \Sigma \alpha_{i} \tau_{i} .{ }^{b}$ Goodness-of-fit. ${ }^{c}\langle\tau\rangle=\sum \alpha_{i} \tau_{i}{ }^{2} / \Sigma$ $\alpha_{i} \tau_{i}=\Sigma f_{i} \tau_{i} \cdot{ }^{d} k_{\mathrm{FL}}=\Phi_{\mathrm{FL}} /<\tau>$. ${ }^{e} k_{\mathrm{nr}} \mathrm{S}=\left(1-\Phi_{\mathrm{FL}}\right) /<\tau>$. ${ }^{f}$ Fitted by three-components exponential decay with one fixed component as scattered light $(\tau=27.7 \mathrm{ps}, f=4.96 \%)$.

The effects of temperature on the photophysical properties were investigated by monitoring photoluminescence spectra with variable temperatures (Figure 3). For the solution sample, the intensity of the emission band drastically increased as the temperature decreased. In the frozen state of the solution at $80 \mathrm{~K}$, intense photoluminescence was observed within the range of 400-650 nm (Figure 3), and the absolute luminescence quantum yield was determined to be 0.92 . The emission peak at $449 \mathrm{~nm}$ was assigned to fluorescence because of its short lifetime ( $3.0 \mathrm{~ns}$, Table 3). The shoulder peak around $430 \mathrm{~nm}$ is likely to be attributable to a vibronic structure, because the lifetimes were almost the same when the signals were detected at 425 and $450 \mathrm{~nm}$ (Figure S6 and Table S4). In addition, distinct peaks were detected at $510 \mathrm{~nm}$ and longer wavelength regions. This emission band was also detected after $1.0 \mathrm{~ms}$ from the excitation and its luminescence lifetime was quite long $(230 \mathrm{~ms})$, while the fluorescence peak completely disappeared under this condition (Figure S8 and Table S5). According to these results, the emission band at the longer wavelength region was assigned to phosphorescence. From the results of the Gaussian deconvolution of the whole photoluminescence spectrum (Figure S9 and Table S6), the fluorescence and the phosphorescence quantum yields were calculated to be 0.80 and 0.12 , respectively (Table 3). Regarding the fluorescence part, the smaller Stokes shift $\left(1851 \mathrm{~cm}^{-1}\right)$ suggests that the relaxed structure of the complex at the singlet excited state $\left(\mathrm{S}_{1}\right)$ is similar to that of the singlet ground state $\left(\mathrm{S}_{0}\right)$. These observations indicate that the nonradiative decay processes of the excited molecule due to the molecular motion and vibration were restricted at $80 \mathrm{~K}$.

a

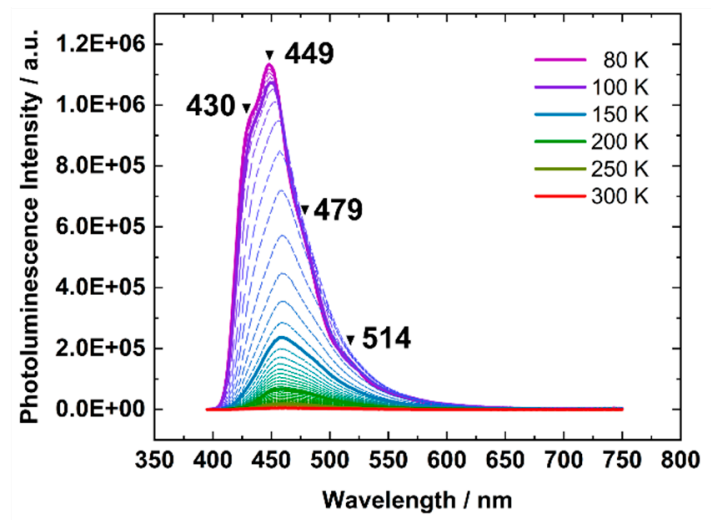

b

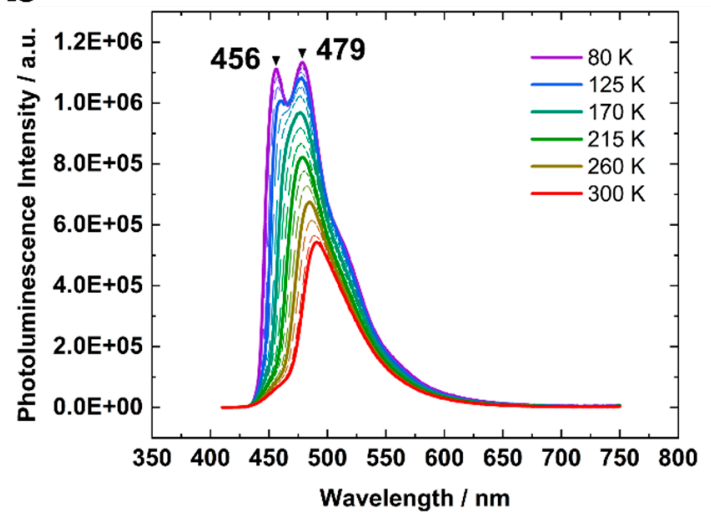

Figure 3. Temperature dependence of photoluminescence spectra of (a) the solution and (b) the crystals. Temperature increments were 5 and $15 \mathrm{~K}$ for the solution and the crystalline samples, respectively.

In the case of the crystalline state at $80 \mathrm{~K}$, the fluorescence band showed a clear vibronic structure and the bathochromic shift to $456 \mathrm{~nm}$ compared with that of the solution at $80 \mathrm{~K}$ (Figure 3b). Taking the condensed situation into account, the bathochromic shift of the first peak probably originates from self-absorption. Indeed, the onset wavelength of the UV-Vis absorption spectrum was obtained around $450 \mathrm{~nm}$ at the solution stage (Figure 2a). In addition, the vibronic peak at $479 \mathrm{~nm}$ was also observed in 
the emission spectrum in the solution at $80 \mathrm{~K}$. These results strongly suggest that the intrinsic electronic nature of the single molecule should not be affected by the crystallization. It is worth noting that the luminescence intensities corresponding to the weak fluorescence band (460 nm) at r.t. dramatically increased as the temperature decreased to $215 \mathrm{~K}$ or below. Moreover, the fluorescence lifetime recorded at $450 \mathrm{~nm}$ was almost identical to that at $480 \mathrm{~nm}$. These results mean that the high energy emission band could be attributed to a vibronic peak (Figure 3b). The fluorescence quantum yield at $80 \mathrm{~K}(0.83$ ) was estimated from the comparison of the integration intensity between the spectra at room temperature and $80 \mathrm{~K}$. This value is comparable to that in the solution state at $80 \mathrm{~K}(0.80)$. The phosphorescence, on the other hand, was slightly observed at $560 \mathrm{~nm}$ when the spectrum was after $1.0 \mathrm{~ms}$ from the excitation (Figure S8b), but the intensity was too weak to determine the phosphorescence quantum yield under this condition (Figure 3b). Defects, impurities and diffusion of excitons in the crystal packing might be responsible for the decrease in the phosphorescence quantum yield due to the relatively long lifetime of the triplet excited state.

\subsection{Theoretical Calculations}

To obtain deep insight on optical behaviors originating from the electronic features of the complex, density functional theory (DFT) and time-dependent DFT (TD-DFT) calculations were performed with the Gaussian 16 rev. B.01 package [50]. We treat only singlet ground and excited states in the following discussion, because the observed phosphorescence quantum yields were relatively low, even at low temperature, as mentioned above. Geometry optimizations and single point energy calculations were carried out at the CAM-B3LYP/6-31+G(d,p) and the CAM-B3LYP/6-311++G(d,p) levels of theory, respectively. Geometry optimizations were performed for singlet ground $\left(\mathrm{S}_{0}\right)$ and first singlet excited $\left(\mathrm{S}_{1}\right)$ states. The single-crystal structure and the optimized structure at the $\mathrm{S}_{0}$ state were employed as the initial geometries for the optimization at the $S_{0}$ and the $S_{1}$ states, respectively. Both optimized structures were confirmed as local minima for each potential energy surface (PES) by using frequency calculations. As shown in Figure S10, the obtained $\mathrm{S}_{0}$ structure is consistent with that in the single crystal.

Figure 4a shows the calculated energy diagrams of the frontier orbitals with the optimized structures and Kohn-Sham highest occupied and lowest unoccupied molecular orbitals (HOMO and LUMO, respectively). For the $S_{0}$ structure, the $S_{0}-S_{1}$ transition energy was estimated to be $3.57 \mathrm{eV}(347 \mathrm{~nm})$, and the transition was composed mainly of the HOMO-LUMO transition (Table 4). Thus, we assign the absorption band in the lowest energy region as the HOMO-LUMO transition. Regarding the central six-membered ring, the distributions of the HOMO and LUMO were consistent with those of pentadienyl anion (Figure $4 \mathrm{~b}$ ), which belongs to the $C_{2 \mathrm{v}}$ point group. Therefore, the symmetry species of the HOMO and the LUMO of LAlH were approximately assigned to $B_{2}$ and $A_{2}$ in the point group, respectively. Considering the direct product of the two symmetry species, the symmetry of the HOMO-LUMO electronic transition is $B_{2}$. Hence, the corresponding electronic transition moment has a non-zero value, then the transition is symmetry-allowed [45]. This fact is consistent with the calculated large oscillator strength of the $S_{0}-S_{1}$ transition of LAlH (Table 4), although the molecular structure of $\mathbf{L A l H}$ is disordered from the $C_{2 \mathrm{v}}$ structure due to the sterically hindered peripheral aromatic groups. Indeed, the relatively large molar absorption coefficient strongly supports the fact that this band is an allowed electronic transition.

Table 4. Results of TD-DFT calculations.

\begin{tabular}{cccccc}
\hline Geometry & Transition & Composition & Coefficient $^{a}$ & $f^{b}$ & $\lambda / \mathbf{n m}^{c}$ \\
\hline $\mathrm{S}_{0}$ geom & $\mathrm{S}_{0}-\mathrm{S}_{1}$ & HOMO-LUMO & 0.68764 & 0.4205 & 347.05 \\
$\mathrm{~S}_{1}$ geom & $\mathrm{S}_{0}-\mathrm{S}_{1}$ & HOMO-LUMO & 0.69035 & 0.3807 & 404.73 \\
\hline \multicolumn{2}{c}{${ }^{a}$ Expansion } \\
\hline
\end{tabular}

\footnotetext{
${ }^{a}$ Expansion coefficients for the electronic transition. ${ }^{b}$ Oscillator strength. ${ }^{c}$ Excitation wavelength.
} 
a

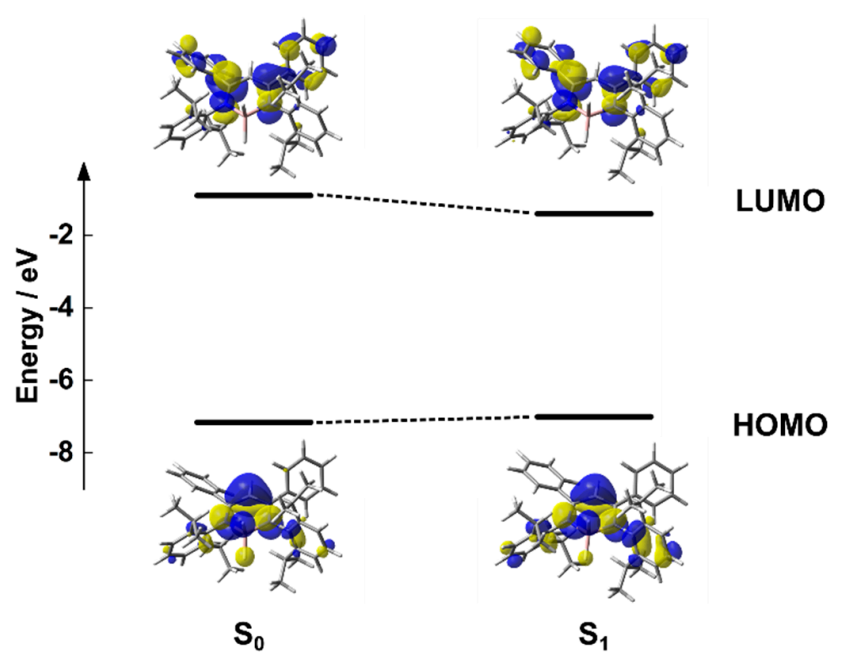

b

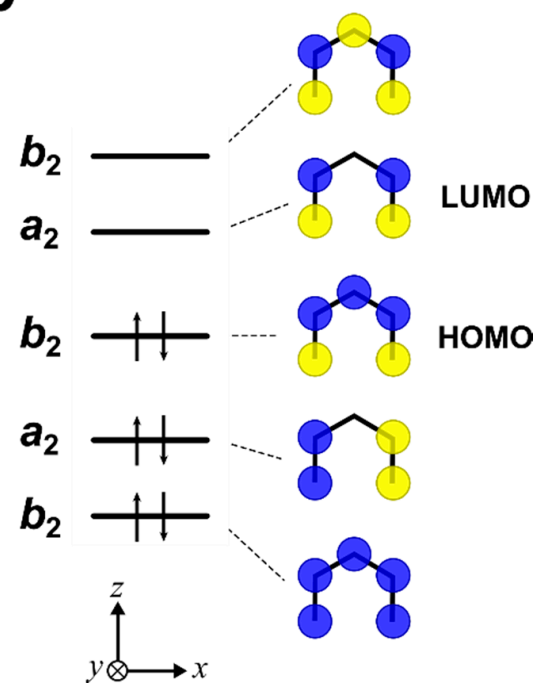

Figure 4. (a) Calculated energy diagrams for the optimized structures at the $S_{0}$ and $S_{1}$ states. Isovalue was set at 0.03. (b) Schematic representation of the orbital symmetries of the pentadienyl anion. Arrows denote electrons.

Since the electronic characteristics of the $S_{1}-S_{0}$ transition for the $S_{1}$ structure is almost the same as that of the $S_{0}$ structure, the calculations revealed that the electronic transition for the $S_{1}$ structure possesses the large oscillator strength (0.3807). In addition, the corresponding Stokes shift $\left(4.1 \times 10^{3} \mathrm{~cm}^{-1}\right)$ can be calculated from the energetic change between the electronic transitions for the $S_{0}$ and $S_{1}$ structures. This value is comparable to the experimental value in the solution at room temperature $\left(4.0 \times 10^{3} \mathrm{~cm}^{-1}\right)$. The experimental luminescence quantum yield, however, was significantly small $(<0.01)$ under the same condition as mentioned above. These results clearly indicate that excited molecules could nonradiatively decay to the ground state through significantly fast vibrational quenching or conical intersections.

To develop advanced luminescence materials, it is essential to reveal an intrinsic origin of the nonradiative quenching paths. For this purpose, we calculated Huang-Rhys (HR) factors [51,52], $S_{i}{ }^{\prime} \mathrm{s}$, for the $S_{1}-S_{0}$ transition (see Supporting Information for details). The HR factor is one of the essential parameters for evaluating the nonradiative decay rate, brought into a series of investigations for the AIE systems by Shuai et al. [53-55]. The HR factor for the $j$-th normal mode $\left(\omega_{j}\right), S_{j}$, is approximately regarded as the average number of phonons (vibrational quanta corresponding to the $j$-th normal mode) emitted through electron-phonon coupling during a nonradiative process (see Supporting Information for details). Consequently, the normal modes corresponding with the large HR factors mainly contribute to the radiationless quenching of the excited state energy. When an excited molecule decays to the ground state, its molecular geometry relaxes to the most stable one. Considering the structural relaxation resulting in the same energetic change (Figure 5a), the displacement of the atomic coordinates $(\Delta Q)$ for typical AIE-active molecules would be larger than that for rigid AIE-inactive molecules $\left(\Delta Q^{\text {AIE Active }}>\Delta Q^{\text {AIE Inactive }}\right)$. This is because these AIE-active ones are composed of movable aromatic moieties on the periphery of the system. In other words, these AIE-gens possess relatively flat PESs compared to the inactive molecules. This means that the normal modes of these molecules could contain very low frequencies. Hence, relatively large HR factors $(>10)$ have appeared in some well-known AIE-active molecules within the range of 10 to $100 \mathrm{~cm}^{-1}$. These low-energy modes are generally attributed to rotational vibration or out-of-plane vibration of a $\pi$-system, like peripheral phenyl groups, in the molecules [53-57]. On the other hand, such low-frequency modes with large HR factors are absent or few for typical AIE-inactive molecules, while these molecules possess smaller $(<1)$ HR factors in the high-frequency region $\left(-1500 \mathrm{~cm}^{-1}\right)$. The corresponding high-energy normal modes are generally assigned to single- or double-bond stretching modes of the $\pi$-conjugated systems [53-57]. 
From these observations, it can be noted that low-energy normal modes with large HR factors can play an essential role in realizing the AIE effect. It should be noted that we still neglect the breakdown of the adiabatic approximation in this regime. To treat the real systems in more accurate manner, we should need further considerations, for example Duschinsky rotation [55-57].

a

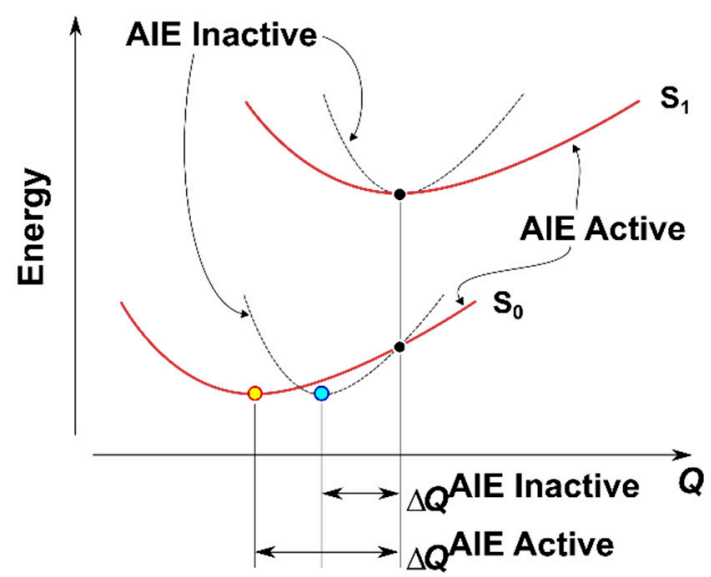

C

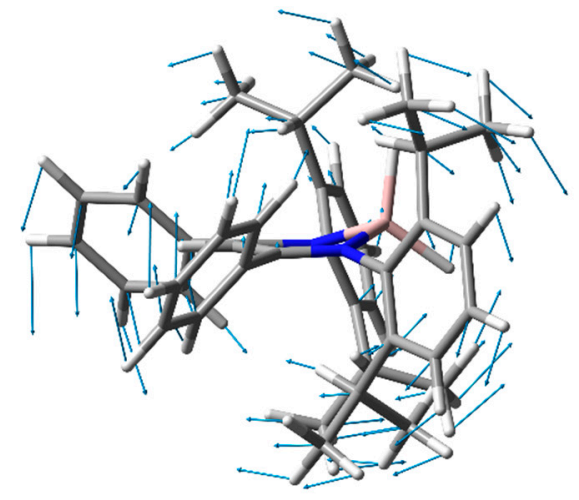

$15.3 \mathrm{~cm}^{-1}$ b

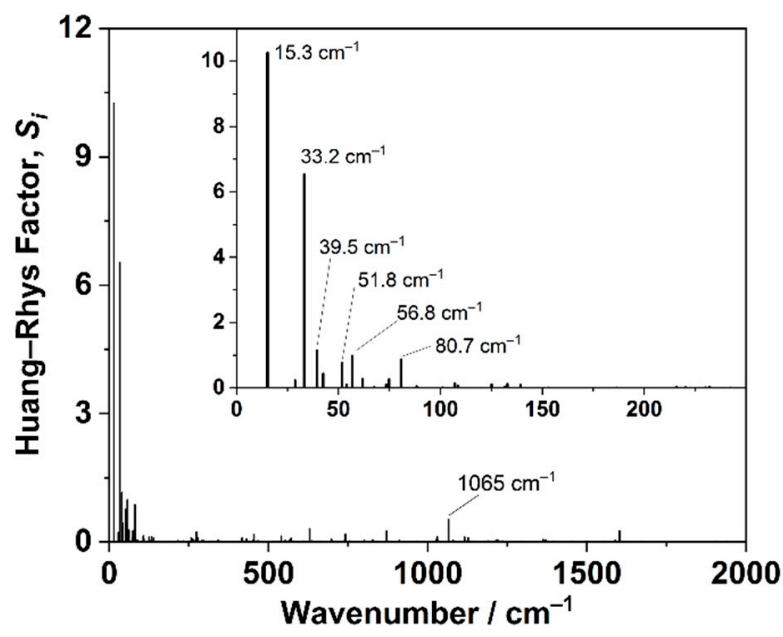

$33.2 \mathrm{~cm}^{-1}$

Figure 5. (a) Schematic representation of potential energy surface diagrams of typical AIE-active and -inactive molecules. Q means reaction coordinates. (b) Calculated Huang-Rhys factors, $S_{i}$, versus the normal modes for LAlH. Inset shows an enlarged view of the low-frequency region. The marked normal modes have relatively large HR factors $\left(S_{i}>0.5\right)$. (c) Displaced vectors for the vibrational modes of $\omega_{1}\left(15.3 \mathrm{~cm}^{-1}\right)$ and $\omega_{3}\left(33.2 \mathrm{~cm}^{-1}\right)$.

The calculated HR factors for LAlH are depicted in Figure 5b, and those selected are listed in Table 5. All normal modes with large HR factors are located within the range from 0 to $100 \mathrm{~cm}^{-1}$. Notably, the significant HR factors appear at $15.3\left(\omega_{1}\right)$ and $33.2 \mathrm{~cm}^{-1}\left(\omega_{3}\right)$. The displacement vectors for $\omega_{1}$ and $\omega_{3}$ are shown in Figure 5c. These normal modes, $\omega_{1}$ and $\omega_{3}$, are mainly attributed to the out-of-plane twisting and the rotational vibration, respectively. These vibrational modes could intrinsically lead to the radiationless decay process of the excited state, although there are other couplings between molecular electronic states and other states, e.g., vibrational modes of solvents. From these data, it is indicated that it might be possible to control the emission properties of the system through the restriction of the vibration utilizing a synthetic methodology. 
Table 5. Selected Huang-Rhys factors and the corresponding normal modes.

\begin{tabular}{cccc}
\hline Mode Index, $\boldsymbol{i}$ & $\boldsymbol{\omega}_{\boldsymbol{i}} / \mathbf{c m}^{\mathbf{1}}$ & $\boldsymbol{S}_{\boldsymbol{i}}$ & $\boldsymbol{\lambda}_{\boldsymbol{i}} / \mathbf{c m}^{\mathbf{- 1} \boldsymbol{a}}$ \\
\hline 1 & 15.2511 & 10.2582 & 156.44883 \\
3 & 33.1647 & 6.53073 & 216.5897 \\
4 & 39.4657 & 1.14514 & 45.19375 \\
6 & 51.8166 & 0.76687 & 39.73634 \\
8 & 56.779 & 0.98173 & 55.74187 \\
13 & 80.6648 & 0.86301 & 69.61493 \\
124 & 1065.3059 & 0.5273 & 561.74006 \\
\hline
\end{tabular}

${ }^{a}$ Reorganization energy determined by $\lambda_{i}=\omega_{i} S_{i}$.

\section{Materials and Methods}

\subsection{Materials}

All reactions were performed under argon or nitrogen atmosphere using modified Schlenk line techniques and an MBRAUN glovebox system UNIlab, unless otherwise noted. Analytical thin layer chromatography (TLC) was performed with silica gel 60 Merck F254 plates. Column chromatography was performed with Wakogel C-200 $\mathrm{SiO}_{2}$. Deoxygenated toluene (FUJIFILM Wako Pure Chemical Industries, Ltd., Tokyo, Japan.; FWPCI), and deoxygenated hexane (FWPCI) were purchased from commercial sources and used as received. $\mathrm{LiAlH}_{4}$ (Tokyo Chemicals Industry Co., Ltd., Tokyo, Japan.) was purified by recrystallization from diethyl ether under inert atmosphere before use. Deuterated benzene was stored with microwave-activated molecular sieves $4 \mathrm{~A}$ (FWPCI) and degassed in a glovebox before use.

\subsection{Synthesis of $\mathrm{LAlH}$}

A $30 \mathrm{~mL}$ Schlenk flask and a stir tip were dried in an oven set at $120{ }^{\circ} \mathrm{C}$ for several hours and taken into a glovebox. The flask was charged with a ligand $(250 \mathrm{mg}, 0.46 \mathrm{mmol})$ and fleshly recrystallized lithium aluminum hydride $(26 \mathrm{mg}, 0.69 \mathrm{mmol})$ in a glovebox and sealed with a rubber septum. To the flask attached to a double manifold was added toluene $(4 \mathrm{~mL})$ at room temperature, and the yellow suspension was allowed to warm to $90^{\circ} \mathrm{C}$. After stirring for $20 \mathrm{~h}$, all volatile compounds were removed under reduced pressure. In a glovebox, the residue was extracted with toluene and filtered with a hydrophobic PTFE filter (Merck Millipore, pore size: $0.20 \mu \mathrm{m}$ ) and a disposable syringe (HSW NORM-JECT ${ }^{\circledR}$ ). The filtrate was concentrated under reduced pressure with a manifold, then transferred into a glovebox and layered by hexane in a vial to grow crystals. After storing for 6 days, a crop of yellow crystals was collected and washed with hexane, then dried in vacuo to give an analytically pure product as bright yellow crystals $(60 \mathrm{mg}, 23 \%) .{ }^{1} \mathrm{H}$ NMR $\left(400 \mathrm{MHz} ; \mathrm{C}_{6} \mathrm{H}_{6}\right)$ $\delta=7.22-7.20(\mathrm{~m}, 4 \mathrm{H}), 7.06-6.98(\mathrm{~m}, 6 \mathrm{H}), 6.81(\mathrm{~m}, 6 \mathrm{H}), 5.64(\mathrm{~s}, 1 \mathrm{H}, \mathrm{C}=\mathrm{CH}-\mathrm{C}), 4.73(\mathrm{br}, 2 \mathrm{H}, \mathrm{AlH}), 3.62$ (sep, $\left.{ }^{3} \mathrm{~J}=6.7 \mathrm{~Hz}, 4 \mathrm{H}, \mathrm{CHMe}\right), 1.44\left(\mathrm{~d},{ }^{3} \mathrm{~J}=6.7 \mathrm{~Hz}, 12 \mathrm{H}, \mathrm{Me}\right), 1.03\left(\mathrm{~d},{ }^{3} \mathrm{~J}=6.7 \mathrm{~Hz}, 12 \mathrm{H}, \mathrm{Me}\right) .{ }^{13} \mathrm{C}$ NMR $\left(101 \mathrm{MHz} ; \mathrm{C}_{6} \mathrm{H}_{6}\right) \delta=171.2,144.6,140.1,139.1,129.2,127.7,127.5,124.7,101.4,28.8,26.7,23.6 .{ }^{1} \mathrm{H}$ NMR $\left(400 \mathrm{MHz} ; \mathrm{CDCl}_{3}\right) \delta=7.24-7.02(\mathrm{~m}, 16 \mathrm{H}), 5.53(\mathrm{~s}, 1 \mathrm{H}, \mathrm{C}=\mathrm{CH}-\mathrm{C}), 4.03(\mathrm{br}, 2 \mathrm{H}, \mathrm{AlH}), 3.31\left(\mathrm{sep},{ }^{3} \mathrm{~J}=6.7\right.$ $\mathrm{Hz}, 4 \mathrm{H}, \mathrm{CHMe}), 1.25\left(\mathrm{~d},{ }^{3} \mathrm{~J}=6.7 \mathrm{~Hz}, 12 \mathrm{H}, \mathrm{Me}\right), 0.97\left(\mathrm{~d},{ }^{3} \mathrm{~J}=6.7 \mathrm{~Hz}, 12 \mathrm{H}, \mathrm{Me}\right) .{ }^{13} \mathrm{C}\left\{{ }^{1} \mathrm{H}\right\} \mathrm{NMR}(101 \mathrm{MHz}$; $\left.\mathrm{CDCl}_{3}\right): \delta=170.7,144.2,139.6,138.5,129.0,128.8,127.4,126.9,124.1,100.9,28.3,26.3,23.4 .{ }^{27} \mathrm{Al}\left\{{ }^{1} \mathrm{H}\right\}$ NMR $\left(130 \mathrm{MHz} ; \mathrm{C}_{6} \mathrm{D}_{6}\right): \delta=65.7 \mathrm{ppm}\left(v_{1 / 2}=170 \mathrm{~Hz}\right)$. HRMS (DART) for $[\mathrm{M}+\mathrm{H}]^{+}$, Found: 571.3620, Calcd.: 571.3627.

\subsection{NMR Spectroscopy}

${ }^{1} \mathrm{H}(400 \mathrm{MHz})$ and ${ }^{13} \mathrm{C}\left\{{ }^{1} \mathrm{H}\right\}(100 \mathrm{MHz})$ NMR spectra were recorded on JEOL JNM-AL400 spectrometer with a J-Young Valve NMR tube. In ${ }^{1} \mathrm{H}$ and ${ }^{13} \mathrm{C}\left\{{ }^{1} \mathrm{H}\right\}$ NMR spectra, tetramethylsilane (TMS) and/or residual solvent peaks were used as internal standards. 
${ }^{27} \mathrm{Al}\left\{{ }^{1} \mathrm{H}\right\}$ NMR $(130 \mathrm{MHz})$ spectra were recorded at the Technical Support Office (Department of Synthetic Chemistry and Biological Chemistry, Graduate School of Engineering, Kyoto University) on a JEOL JNM-ECZ500 spectrometer and referenced to $1.0 \mathrm{M} \mathrm{Al}\left(\mathrm{NO}_{3}\right)_{3} \cdot 9 \mathrm{H}_{2} \mathrm{O}$ in $\mathrm{D}_{2} \mathrm{O}(0 \mathrm{ppm})$ as an external standard. Phase correction was not able to be performed reasonably for the sample containing LAlH due to the wavy baseline. Hence the phasing parameters of the measurement for the external standard were used for the sample as well.

\subsection{High Resolution Mass Spectrometry}

High-resolution mass (HRMS) spectrometry was performed at the Technical Support Office (Department of Synthetic Chemistry and Biological Chemistry, Graduate School of Engineering, Kyoto University), and the HRMS spectra were obtained on a Thermo Fisher Scientific EXACTIVE spectrometer for electrospray ionization (ESI) and for direct analysis in real time (DART).

\subsection{Single Crystal X-Ray Analysis}

Single crystals were grown in a glovebox from toluene/hexane mixed solution at room temperature to $10^{\circ} \mathrm{C}$. A crystal in liquid paraffin was scooped with a sampling loop inside the glovebox, then mounted on a goniometer and cooled to $93 \mathrm{~K}$ with $\mathrm{N}_{2}$ gas stream as soon as possible. Liquid paraffin was stored in a vial with divided elemental potassium in a glovebox for several months before use.

X-ray diffraction data were collected using a Rigaku R-AXIS RAPID-F. Data were collected at $93 \mathrm{~K}$ with graphite-monochromated Mo $\mathrm{K} \alpha$ radiation diffractometer and an imaging plate. Equivalent reflections were merged, and a symmetry related absorption correction was carried out with the program ABSCOR [58]. The structures were solved with SHELXT 2014 [59] and refined on $F^{2}$ with SHELXL [60] on Yadokari-XG [61] or Shelxle [62]. Two hydrogen atoms bonding to an aluminum atom were located from a $\Delta F$ map and refined freely with $U_{\text {iso }}$ set to 1.5 -fold of $U_{\text {eq }}$ of the aluminum atom. The other hydrogen atoms were refined with a riding model. The program ORTEP-3 [63] was used to generate the X-ray structural diagram.

\subsection{Photophysical Measurements}

UV-vis absorption spectra were recorded on a SHIMADZU UV-3600 spectrophotometer. Fluorescence and phosphorescence emission spectra and phosphorescence decay were measured with a HORIBA JOBIN YVON Fluorolog-3 spectrofluorometer and an Oxford Optistat DN for temperature control. Absolute photoluminescence quantum yields were measured with a Hamamatsu Photonics Quantaurus-QY Plus C13534-01 and a sample holder for low temperature A11238-05 was used for the measurements at $77 \mathrm{~K}$. Fluorescence lifetimes were measured by a Horiba FluoroCube spectrofluorometer system with an Oxford Optistat DN for temperature control and a UV diode laser (NanoLED $375 \mathrm{~nm}$ ).

\section{Conclusions}

We synthesized the CIE-active $\beta$-diketiminate dihydroaluminum complex through the reaction of lithium aluminum hydride and the corresponding ligand. The synthesized molecule presents fluorescence in the crystal at room temperature, while it hardly emits in the solution state at room temperature. The results of variable temperature photoluminescence spectroscopy and TD-DFT calculations suggested that the out-of-plane twisting and the rotational vibration suppressed the radiative decay process in the solution state at room temperature. Finally, we discovered that the complex exhibited nearly quantitative luminescence in the solution state at $80 \mathrm{~K}$, including weak phosphorescence with a long lifetime. From these optical properties, it can be expected that the $\beta$-diketiminate ligand structure could open a new window for developing a new class of solid-state luminescent materials by further modification. 
Supplementary Materials: The following are available online at http://www.mdpi.com/2304-6740/7/8/100/s1; Figure S1: (a) ${ }^{1} \mathrm{H}$ and (b) ${ }^{13} \mathrm{C}\left\{{ }^{1} \mathrm{H}\right\}$ NMR spectra of LAlH in $\mathrm{CDCl}_{3}$, Figure S2: (a) ${ }^{1} \mathrm{H}$ and (b) ${ }^{13} \mathrm{C}\left\{{ }^{1} \mathrm{H}\right\} \mathrm{NMR}$ spectra of LAlH in $\mathrm{C}_{6} \mathrm{D}_{6}$, Figure S3: ${ }^{27} \mathrm{Al}\left\{{ }^{1} \mathrm{H}\right\}$ NMR spectrum of LAlH in $\mathrm{C}_{6} \mathrm{D}_{6} \cdot \mathrm{Al}\left(\mathrm{NO}_{3}\right)_{3} \cdot 9 \mathrm{H}_{2} \mathrm{O}$ in $\mathrm{D}_{2} \mathrm{O}$ was used as an external standard (0 ppm), Figure S4: Packing diagram of LAlH viewed along with (a) $a$ and (b) $b$ axes. All hydrogen atoms were omitted for clarity. Isopropyl groups were shown in wireframe. Legends: red bar, $a$ axis; green bar, $b$ axis; and blue bar, $c$ axis. Key to atom color: carbon, copper and green; aluminum, magenta; and nitrogen, blue, Figure S5: UV-Vis absorption spectrum (blue circles) and the fitted curve (black line), Figure S6: Fluorescence decay curves of LAlH (a) in the crystalline state at r.t. detected at 450 (cyan triangles) and 481 $\mathrm{nm}$ (blue circles) and (b) in the solution state at $80 \mathrm{~K}$. Fitted curves were shown as solid lines, Figure S7: Simple Jablonski diagram for LAlH, Figure S8: Phosphorescence spectra of LAlH at $80 \mathrm{~K}$ in (a) the solution and (b) crystalline states. The spectra were recorded after $1.0 \mathrm{~ms}$ from the excitation. Insets show the corresponding phosphorescence decay curves, Figure S9: Deconvoluted photoluminescence spectrum of LAlH in the solution state at $80 \mathrm{~K}$, Figure S10: Superimposed structures of (a) the single-crystal (blue) and the $\mathrm{S}_{0}$ optimized (magenta) structures, and (b) $S_{0}$ (magenta) and $S_{1}$ (green) optimized structures, Table S1: Selected X-ray data, collection and refinement parameters for LAlH, Table S2: Fitted parameters for the UV-vis spectrum, Table S3: Parameters for estimation of $k_{\mathrm{FL}}{ }^{0}$, Table S4: Fitted parameters for fluorescence lifetime measurements of the crystals at r.t., Table S5: Phosphorescence lifetimes of LAlH at 80 K, Table S6: Results of deconvolution of the photoluminescence spectrum, Table S7: Optimized geometry of LAlH at the $S_{0}$ state, Table S8: Optimized geometry of LAlH at the $S_{1}$ state, Table S9: Result of TD-DFT calculation for LAlH at the $S_{0}$ geometry, Table S10: Result of TD-DFT calculation for LAlH at the $S_{1}$ geometry.

Author Contributions: Conceptualization, S.I. and K.T.; data curation, S.I. and K.T.; formal analysis, S.I.; funding acquisition, S.I., K.T. and Y.C.; investigation, S.I.; methodology, S.I.; project administration, K.T. and Y.C.; supervision, K.T. and Y.C.; visualization, S.I.; writing—original draft, S.I.; writing—review \& editing, S.I., K.T. and Y.C.

Funding: This research was partially supported by a Grant-in-Aid for JSPS Research Fellow (17J10444), (B) (JP17H03067) and for Challenging Research (Pioneering) (JP18H05356).

Acknowledgments: Computation time was provided by the Supercomputer System, Institute for Chemical Research, Kyoto University.

Conflicts of Interest: The authors declare no conflict of interest.

\section{References}

1. Finholt, A.E.; Bond, A.C.; Schlesinger, H.I. Lithium Aluminum Hydride, Aluminum Hydride and Lithium Gallium Hydride, and Some of their Applications in Organic and Inorganic Chemistry. J. Am. Chem. Soc. 1947, 69, 1199-1203. [CrossRef]

2. Li, W.; Ma, X.; Walawalkar, M.G.; Yang, Z.; Roesky, H.W. Soluble aluminum hydrides function as catalysts in deprotonation, insertion, and activation reactions. Coord. Chem. Rev. 2017, 350, 14-29. [CrossRef]

3. Tang, C.W.; VanSlyke, S.A. Organic electroluminescent diodes. Appl. Phys. Lett. 1987, 51, 913-915. [CrossRef]

4. Wang, S. Luminescence and electroluminescence of $\mathrm{Al}(\mathrm{III}), \mathrm{B}(\mathrm{III}), \mathrm{Be}(\mathrm{II})$ and $\mathrm{Zn}$ (II) complexes with nitrogen donors. Coord. Chem. Rev. 2001, 215, 79-98. [CrossRef]

5. Zhao, S.; Wang, S. Luminescence and reactivity of 7-azaindole derivatives and complexes. Chem. Rev. 2010, 39, 3142-3156. [CrossRef] [PubMed]

6. Yang, Z.; Zhong, M.; Ma, X.; Nijesh, K.; De, S.; Parameswaran, P.; Roesky, H.W. An Aluminum Dihydride Working as a Catalyst in Hydroboration and Dehydrocoupling. J. Am. Chem. Soc. 2016, 138, 2548-2551. [CrossRef]

7. Piers, W. Non-cyclopentadienyl ancillaries in organogroup 3 metal chemistry: A fine balance in ligand design. Coord. Chem. Rev. 2002, 233-234, 131-155. [CrossRef]

8. Bourget-Merle, L.; Lappert, M.F.; Severn, J.R. The Chemistry of $\beta$-Diketiminatometal Complexes. Chem. Rev. 2002, 102, 3031-3066. [CrossRef]

9. Roesky, H.W.; Singh, S.; Jancik, V.; Chandrasekhar, V. A Paradigm Change in Assembling OH Functionalities on Metal Centers. Acc. Chem. Res. 2004, 37, 969-981. [CrossRef]

10. Wu, J.; Yu, T.-L.; Chen, C.-T.; Lin, C.-C. Recent developments in main group metal complexes catalyzed/initiated polymerization of lactides and related cyclic esters. Coord. Chem. Rev. 2006, 250, 602-626. [CrossRef]

11. Hill, M.S.; Hitchcock, P.B.; Pongtavornpinyo, R. A Linear Homocatenated Compound Containing Six Indium Centers. Science 2006, 311, 1904-1907. [CrossRef] [PubMed]

12. Mindiola, D.J. Nacnac ... Are You Still There? The Evolution of $\beta$-Diketiminate Complexes of Nickel. Angew. Chem. Int. Ed. 2009, 48, 6198-6200. [CrossRef] [PubMed]

13. Tsai, Y.C. The chemistry of univalent metal $\beta$-diketiminates. Coord. Chem. Rev. 2012, 256, 722-758. [CrossRef] 
14. Bakthavachalam, K.; Reddy, N.D. Synthesis of Aluminum Complexes of Triaza Framework Ligands and Their Catalytic Activity toward Polymerization of $\varepsilon$-Caprolactone. Organometallics 2013, 32, 3174-3184. [CrossRef]

15. Chen, C.; Bellows, S.M.; Holland, P.L. Tuning steric and electronic effects in transition-metal $\beta$-diketiminate complexes. Dalton Trans. 2015, 44, 16654-16670. [CrossRef]

16. Camp, C.; Arnold, J. On the non-innocence of "Nacnacs": Ligand-based reactivity in $\beta$-diketiminate supported coordination compounds. Dalton Trans. 2016, 45, 14462-14498. [CrossRef] [PubMed]

17. Cui, C.; Roesky, H.W.; Schmidt, H.G.; Noltemeyer, M.; Hao, H.; Cimpoesu, F. Synthesis and structure of a monomeric aluminum(I) compound [ $\left.\left\{\mathrm{HC}(\mathrm{CMeNAr})_{2}\right\} \mathrm{Al}\right]\left(\mathrm{AR}=2,6-i \mathrm{Pr}_{2} \mathrm{C}_{6} \mathrm{H}_{3}\right)$ : A stable aluminum analogue of a carbene. Angew. Chem. Int. Ed. 2000, 39, 4274-4276. [CrossRef]

18. Roesky, H.W.; Kumar, S.S. Chemistry of aluminium(I). Chem. Commun. 2005, 32, 4027-4038. [CrossRef]

19. Nagendran, S.; Roesky, H.W. The Chemistry of Aluminum(I), Silicon(II), and Germanium(II). Organometallics 2008, 27, 457-492. [CrossRef]

20. Chu, T.; Nikonov, G.I. Oxidative Addition and Reductive Elimination at Main-Group Element Centers. Chem. Rev. 2018, 118, 3608-3680. [CrossRef]

21. Bakewell, C.; White, A.J.P.; Crimmin, M.R. Reactions of Fluoroalkenes with an Aluminium(I) Complex. Angew. Chem. Int. Ed. 2018, 57, 6638-6642. [CrossRef]

22. Macedo, F.P.; Gwengo, C.; Lindeman, S.V.; Smith, M.D.; Gardinier, J.R. $\beta$-Diketonate, $\beta$-Ketoiminate, and $\beta$-Diiminate Complexes of Difluoroboron. Eur. J. Inorg. Chem. 2008, 2008, 3200-3211. [CrossRef]

23. Yoshii, R.; Hirose, A.; Tanaka, K.; Chujo, Y. Boron Diiminate with Aggregation-Induced Emission and Crystallization-Induced Emission-Enhancement Characteristics. Chem. Eur. J. 2014, 20, 8320-8324. [CrossRef]

24. Yoshii, R.; Hirose, A.; Tanaka, K.; Chujo, Y. Functionalization of Boron Diiminates with Unique Optical Properties: Multicolor Tuning of Crystallization-Induced Emission and Introduction into the Main Chain of Conjugated Polymers. J. Am. Chem. Soc. 2014, 136, 18131-18139. [CrossRef]

25. Ito, S.; Hirose, A.; Yamaguchi, M.; Tanaka, K.; Chujo, Y. Size-discrimination of volatile organic compounds utilizing gallium diiminate by luminescent chromism of crystallization-induced emission via encapsulation-triggered crystal-crystal transition. J. Mater. Chem. C 2016, 4, 5564-5571. [CrossRef]

26. Yamaguchi, M.; Ito, S.; Hirose, A.; Tanaka, K.; Chujo, Y. Modulation of sensitivity to mechanical stimulus in mechanofluorochromic properties by altering substituent positions in solid-state emissive diiodo boron diiminates. J. Mater. Chem. C 2016, 4, 5314-5319. [CrossRef]

27. Ito, S.; Hirose, A.; Yamaguchi, M.; Tanaka, K.; Chujo, Y. Synthesis of Aggregation-Induced Emission-Active Conjugated Polymers Composed of Group 13 Diiminate Complexes with Tunable Energy Levels via Alteration of Central Element. Polymers 2017, 9, 68. [CrossRef]

28. Tanaka, K.; Chujo, Y. Luminescent color tuning with polymer films composed of boron diiminate conjugated copolymers by changing the connection points to comonomers. Polym. Chem. 2018, 9, 1942-1946.

29. Hong, Y.; Lam, J.W.Y.; Tang, B.Z. Aggregation-induced emission. Chem. Soc. Rev. 2011, 40, 5361-5388. [CrossRef]

30. Mei, J.; Leung, N.L.C.; Kwok, R.T.K.; Lam, J.W.Y.; Tang, B.Z. Aggregation-Induced Emission: Together We Shine, United We Soar! Chem. Rev. 2015, 115, 11718-11940. [CrossRef]

31. Chi, Z.; Zhang, X.; Xu, B.; Zhou, X.; Ma, C.; Zhang, Y.; Liu, S.; Xu, J. Recent advances in organic mechanofluorochromic materials. Chem. Soc. Rev. 2012, 41, 3878-3896. [CrossRef]

32. Matsumura, Y.; Ishidoshiro, M.; Irie, Y.; Imoto, H.; Naka, K.; Tanaka, K.; Inagi, S.; Tomita, I. Arsole-Containing $\pi$-Conjugated Polymer by the Post-Element-Transformation Technique. Angew. Chem. Int. Ed. 2016, 55, 15040-15043. [CrossRef]

33. Zhang, G.; Chen, J.; Payne, S.J.; Kooi, S.E.; Demas, J.N.; Fraser, C.L. Multi-Emissive Difluoroboron Dibenzoylmethane Polylactide Exhibiting Intense Fluorescence and Oxygen-Sensitive Room-Temperature Phosphorescence. J. Am. Chem. Soc. 2007, 129, 8942-8943. [CrossRef]

34. Zhang, G.; Lu, J.; Sabat, M.; Fraser, C.L. Polymorphism and Reversible Mechanochromic Luminescence for Solid-State Difluoroboron Avobenzone. J. Am. Chem. Soc. 2010, 132, 2160-2162. [CrossRef]

35. Ito, H.; Saito, T.; Oshima, N.; Kitamura, N.; Ishizaka, S.; Hinatsu, Y.; Wakeshima, M.; Kato, M.; Tsuge, K.; Sawamura, M. Reversible Mechanochromic Luminescence of $\left[\left(\mathrm{C}_{6} \mathrm{~F}_{5} \mathrm{Au}\right)_{2}(\mu-1,4\right.$-Diisocyanobenzene $\left.)\right]$. J. Am. Chem. Soc. 2008, 130, 10044-10045. [CrossRef] 
36. Zhao, D.; Li, G.; Wu, D.; Qin, X.; Neuhaus, P.; Cheng, Y.; Yang, S.; Lu, Z.; Pu, X.; Long, C.; et al. Regiospecific N-Heteroarylation of Amidines for Full-Color-Tunable Boron Difluoride Dyes with Mechanochromic Luminescence. Angew. Chem. Int. Ed. 2013, 52, 13676-13680. [CrossRef]

37. Wang, L.; Wang, K.; Zou, B.; Ye, K.; Zhang, H.; Wang, Y. Luminescent Chromism of Boron Diketonate Crystals: Distinct Responses to Different Stresses. Adv. Mater. 2015, 27, 2918-2922. [CrossRef]

38. Hirai, Y.; Nakanishi, T.; Kitagawa, Y.; Fushimi, K.; Seki, T.; Ito, H.; Hasegawa, Y. Triboluminescence of Lanthanide Coordination Polymers with Face-to-Face Arranged Substituents. Angew. Chem. Int. Ed. 2017, 56, 7171-7175. [CrossRef]

39. Gon, M.; Tanaka, K.; Chujo, Y. Recent progress in the development of advanced element-block materials. Polym. J. 2018, 50, 109-126. [CrossRef]

40. Gon, M.; Tanaka, K.; Chujo, Y. Creative Synthesis of Organic-Inorganic Molecular Hybrid Materials. Bull. Chem. Soc. Jpn. 2017, 90, 463-474. [CrossRef]

41. Yang, Y.; Li, H.; Wang, C.; Roesky, H.W. Studies of the Ligand Effect on the Synthesis of Dialuminoxanes by Various $\beta$-Diketiminato Ligands. Inorg. Chem. 2012, 51, 2204-2211. [CrossRef]

42. Arrowsmith, M.; Crimmin, M.R.; Hill, M.S.; Kociok-Köhn, G. Beryllium derivatives of a phenyl-substituted $\beta$-diketiminate: A well-defined ring opening reaction of tetrahydrofuran. Dalton Trans. 2013, 42, 9720-9726. [CrossRef]

43. Jana, B.; Uhl, W. New aluminum and gallium complexes of $\beta$-diketiminato and $\beta$-ketiminato ligands. Inorganica Chim. Acta 2017, 455, 61-69. [CrossRef]

44. Lee, S.K.; Lee, S.B.; Park, S.Y.; Yi, Y.S.; Ahn, C.W. Structure of Amorphous Aluminum Oxide. Phys. Rev. Lett. 2009, 103, 095501. [CrossRef]

45. Salem, L. Molecular Orbital Theory of Conjugated Systems; W. A. Benjamin, Inc.: New York, NY, USA, 1966; ISBN 0805384014.

46. Twamley, B.; Hardman, N.J.; Power, P.P. A primary monomeric alane: [N,N'-bis(2,6-diisopropylphenyl) pentane-2,4-diiminato- $\left.N, N^{\prime}\right]$ dihydridoaluminium. Acta Crystallogr. Sect. E Struct. Rep. Online 2001, 57, m227-m228. [CrossRef]

47. González-Gallardo, S.; Jancik, V.; Cea-Olivares, R.; Toscano, R.A.; Moya-Cabrera, M. Preparation of Molecular Alumoxane Hydrides, Hydroxides, and Hydrogensulfides. Angew. Chem. Int. Ed. 2007, 46, 2895-2898. [CrossRef]

48. Stender, M.; Eichler, B.E.; Hardman, N.J.; Power, P.P.; Prust, J.; Noltemeyer, M.; Roesky, H.W. Synthesis and Characterization of $\mathrm{HC}\left\{\mathrm{C}(\mathrm{Me}) \mathrm{N}\left(\mathrm{C}_{6} \mathrm{H}_{3}-2,6-i-\mathrm{Pr}_{2}\right)\right\}_{2} \mathrm{MX}_{2}(\mathrm{M}=\mathrm{Al}, \mathrm{X}=\mathrm{Cl}, \mathrm{I} ; \mathrm{M}=\mathrm{Ga}$, In, $\mathrm{X}=\mathrm{Me}, \mathrm{Cl}$, I): Sterically Encumbered $\beta$-Diketiminate Group 13 Metal Derivatives. Inorg. Chem. 2001, 40, 2794-2799. [CrossRef]

49. Strickler, S.J.; Berg, R.A. Relationship between Absorption Intensity and Fluorescence Lifetime of Molecules. J. Chem. Phys. 1962, 37, 814-822. [CrossRef]

50. Gaussian 16; Revision B.01; Gaussian, Inc.: Wallingford, CT, USA, 2016.

51. Huang, K.; Rhys, A. Theory of light absorption and non-radiative transitions in F-centres. Proc. R. Soc. Lond. Ser. A. Math. Phys. Sci. 1950, 204, 406-423.

52. Kubo, R. Thermal Ionization of Trapped Electrons. Phys. Rev. 1952, 86, 929-937. [CrossRef]

53. Yu, G.; Yin, S.; Liu, Y.; Chen, J.; Xu, X.; Sun, X.; Ma, D.; Zhan, X.; Peng, Q.; Shuai, Z.; et al. Structures, Electronic States, Photoluminescence, and Carrier Transport Properties of 1,1-Disubstituted 2,3,4,5-Tetraphenylsiloles. J. Am. Chem. Soc. 2005, 127, 6335-6346. [CrossRef]

54. Yin, S.; Peng, Q.; Shuai, Z.; Fang, W.; Wang, Y.-H.; Luo, Y. Aggregation-enhanced luminescence and vibronic coupling of silole molecules from first principles. Phys. Rev. B 2006, 73, 205409. [CrossRef]

55. Peng, Q.; Yi, Y.; Shuai, Z.; Shao, J. Toward Quantitative Prediction of Molecular Fluorescence Quantum Efficiency: Role of Duschinsky Rotation. J. Am. Chem. Soc. 2007, 129, 9333-9339. [CrossRef]

56. Peng, Q.; Niu, Y.; Wu, Q.; Gao, X.; Shuai, Z. Theoretical Understanding of AIE Phenomena Through Computational Chemistry. In Aggregation-Induced Emission: Fundamentals; John Wiley and Sons Ltd.: Chichester, UK, 2013; pp. 357-398.

57. Jin, J.-L.; Geng, Y.; Su, Z.-M. Recent Theoretical Advances in Understanding the Mechanism of Aggregation-Induced Emission for Small Organic Molecules. In Aggregation-Induced Emission: Fundamentals; John Wiley and Sons Ltd.: Chichester, UK, 2013; pp. 399-418.

58. Higashi, T. ABSCOR. Program for Absorption Correction; Rigaku Corporation: Tokyo, Japan, 1995. 
59. Sheldrick, G.M. SHELXT - Integrated space-group and crystal-structure determination. Acta Crystallogr. Sect. A Found. Adv. 2015, A71, 3-8. [CrossRef]

60. Sheldrick, G.M. Crystal structure refinement with SHELXL. Acta Crystallogr. Sect. C Struct. Chem. 2015, C71, 3-8. [CrossRef]

61. Wakita, K.; Yadokari, X.G. Program for Crystal Structure Analysis. 2000.

62. Hübschle, C.B.; Sheldrick, G.M.; Dittrich, B. ShelXle: a Qt graphical user interface for SHELXL. J. Appl. Crystallogr. 2011, 44, 1281-1284. [CrossRef]

63. Farrugia, L.J. ORTEP-3 for Windows - a version of ORTEP-III with a Graphical User Interface (GUI). J. Appl. Crystallogr. 1997, 30, 565. [CrossRef]

(C) 2019 by the authors. Licensee MDPI, Basel, Switzerland. This article is an open access article distributed under the terms and conditions of the Creative Commons Attribution (CC BY) license (http://creativecommons.org/licenses/by/4.0/). 